\title{
Bone microstructure and relative age of the holotype specimen of the diplodocoid sauropod dinosaur Suuwassea emilieae
}

\author{
Brandon P. Hedrick, Allison R. Tumarkin-Deratzian, and Peter Dodson \\ Acta Palaeontologica Polonica 59 (2), 2014: 295-304 doi: http://dx.doi.org/10.4202/app.2012.0049
}

We present the first study of bone microstructure in Suuwassea emilieae, a diplodocoid sauropod from the Morrison

Formation. Although the holotype of Suuwassea was recently identified as a subadult, bone histology demonstrates that this individual had reached sexual maturity at approximately $75-80 \%$ of maximum adult size. The smaller size of the holotype of Suuwassea relative to contemporary sauropods is due to ontogeny rather than a true reflection of adult size. A fully adult individual would have likely been similar in size to a fully adult specimen of Apatosaurus. Suuwassea has a number of plesiomorphic characters that might have been explained by its supposed early ontogenetic status, and would then have called the validity of the taxon into question. However, our demonstration that it was an adult confirms that these features represent retention of plesiomorphic character states or evolutionary reversals in a derived animal. Additionally, the specimen shows extensive cortical drift and secondary osteon formation related to skeletal loading, which is often obscured by complete remodeling of Haversian systems in sauropod taxa. There are substantial differences in the microstructure across the bone, which could make histologic samples not based upon complete cross sections problematic. Suuwassea is one of four currently recognized dicraeosaurid taxa, and this study contributes potential taxonomic characters in sauropod bone microstructure.

Key words: Dinosauria, Sauropoda, Suuwassea, histology, Jurassic, Morrison Formation, Montana, USA.

Brandon P. Hedrick [bhedrick@sas.upenn.edu] and Allison R. Tumarkin-Deratzian [altd@temple.edu ], Department of Earth and Environmental Science, University of Pennsylvania, Philadelphia, Pennsylvania, USA; Peter Dodson [dodsonp@vet.upenn.edu] School of Veterinary Medicine, Department of Animal Biology, University of Pennsylvania, USA and Department of Earth and Environmental Science, University of Pennsylvania, Philadelphia, Pennsylvania, USA. 
This is an open-access article distributed under the terms of the Creative Commons

Attribution License (for details please see creativecommons.org), which permits unrestricted use, distribution, and reproduction in any medium, provided the original author and source are credited.

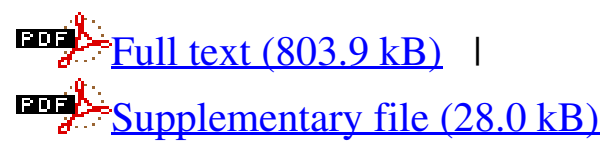

